\section{A tradition of mobility and ephemeral micro-urbanism. Summer vacations South of lquique}

PALABRAS CLAVE - MOVILIDAD TRADICIONAL MICROURBANISMO EFIMERO $\cdot$ ARPUITECTURA COSTERA TARAPAPUEÑA · VERANEO EN I PUIPUE. ESPACIOS INTERNODALES

KEYWORDS • TRADITIONAL MOBILITY · MICROURBANISM - WATERFRONT ARCHITECTURE IN TARAPACÁ. - WATERFRONT ARCHITECTURE IN TARAPACA.
SUMMERVACATION IN IOUIOUE · INTERNODAL SPACES

\title{
Tradición de movilidad y microurbanismo efímero
}

\section{Veraneo al sur de lquique*}

\author{
MG. MANUEL CORVALÁN VILCHES · Universidad Arturo Prat, lquique, Chile · macorval@unap.cl
}

Fecha de recepción: 07 de junio de 2018 · Fecha de aceptación: 02 de octubre de 2018

\section{INTRODUCCIÓN}

RESUMEN

Este artículo presenta la movilidad en la Región de Tarapacá como una expresión de organización del espacio habitable, donde se vincula la extensión territorial de los nodos urbanos con asentamientos efímeros de ocupaciones temporales. Durante los distintos procesos de ocupación, las prácticas culturales de intercambio han nutrido de significantes patrimoniales a la relación hombre-espacioterritorio, lo que se visualiza en las maneras de entender el vínculo del tarapaqueño con respuestas arquitectónicas efímeras que configuran el habitar en espacios internodales. En la actualidad, esta herencia cultural se ve reflejada en la ocupación estival de la costa, donde frente al actual crecimiento de lquique y su consecuente planificación de extensión, la actividad veraniega de acampar en configuraciones microurbanas puede verse desplazada junto a las actividades patrimoniales que allí se suceden.

\section{ABSTRACT}

This article deals with mobility in the Tarapacá Region as an expression of organization of habitable space, where territorial extension of urban nodes is linked to the ephemeral settlements of temporary occupations. During the different processes of occupation, the human-space-territory relationship has been nurtured with significant heritage by cultural exchange practices. This fact can be observed in the way people from Tarapacá understand the link with the phenomenon of ephemeral architectural responses that shape the inhabiting inter-nodal space. At present, this cultural heritage is reflected in the takeover of coastal borders in the summer, where faced with the continuing growth of lquique and its subsequent extension of urban planning, summer vacation activities related to camping in micro-urban configurations may be displaced along with the heritage activities that take place there.
Los estudios de la ocupación de Tarapacá y de la movilidad generada por circuitos de comunicación en la región, se han presentado como una manera de entender la modificación del territorio -tanto física como simbólicamente- desplegándose a modo de la primera manifestación arquitectónica en el espacio habitado. La huella del hombre como vestigio del andar ha indicado la necesidad de comunicación e intercambio entre los primeros habitantes de la región. Ya desde los "desarrollos regionales", en el ambiente costero tarapaqueño se comenzaron a definir asentamientos de explotación de recursos marinos que marcaron una primera instancia de detención.

El moverse por Tarapacá constituye una tradición presente desde épocas prehispánicas y que se ha ido replicando en todas las etapas históricas consecutivas: con la expansión del Tawantinsuyu, la extracción de la plata, los intercambios agrícolas, el auge del salitre, la devoción religiosa y, finalmente, gracias a la llegada del vehículo. El atravesar territorios para generar asentamientos efímeros en los espacios que se encuentran entre los nodos urbanos, ha sido una estrategia presente gracias al movimiento de grupos caravaneros en las fases iniciales hasta la configuración actual de agrupamientos colectivos veraniegos en la costa al sur de lquique.

La evidencia de un paisaje edificado efímero mediante unidades arquitectónicas y sus agrupaciones, caracterizadas por su relación con la flexibilidad y adaptabilidad programática, se presenta como una reflexión sobre el espacio habitado, ya que son los elementos de fácil montaje constructivo los que dan cabida a la permanencia.

\section{METODOLOGÍA}

La comprensión del territorio a través de la movilidad, se realiza con la revisión directa de autores que describen el proceso de ocupación regional desde una perspectiva arqueológicahistórica. Se observan los vínculos con la costa y visualiza cómo allí se han producido prácticas socioculturales con evidencias materiales.

* Artículo escrito para la obtención del grado de Magíster en Patrimonio Intangible, Sociedad y Desarrollo Territorial. Proyecto "Puesta en valor digital y formación del capital humano, para el patrimonio intangible de Tarapacá", financiado por el Fondo de Innovación para la Competitividad (FIC) del Gobierno Regional de Tarapacá y ejecutado por el Instituto de Estudios Andinos Isluga de la Universidad Arturo Prat (www.tarapacaenelmundo.cl). 
Luego se aborda la organización contemporánea del espacio habitable periférico costero de lquique durante los veranos, estableciendo patrones de ocupación que revelan situaciones urbanas de menor escala. El estudio se aborda con fotografías aéreas, entrevistas a actores relevantes y revisión de documentos para enfocar descriptivamente el objeto arquitectónico y sus agrupaciones.

Las manifestaciones de ocupación temporal del espacio y sus posibilidades de desplazamiento son expuestas para visualizar las implicancias de la expansión del límite urbano de la ciudad de lquique.

\section{RESULTADOS}

\section{HOMBRE Y MOVILIDAD EN EL DESARROLLO TARAPAQUEÑO}

La región de Tarapacá se caracteriza por cinco agroecosistemas; altiplano, quebradas, oasis, pampa y costa (Carevic, 2013, p. 11), es un territorio donde desde el formativo sus poblaciones han mantenido una constante y alta movilidad, "seguramente bajo el mismo patrón arcaico, con asentamientos pasajeros" (Uribe, 2009, p. 24), que se deben principalmente al movimiento pastoreo-caravanero, como resultado de la complementariedad ecológica e intercambio transhumántico entre las tierras altas y la costa, y viceversa con desvío a zonas interiores marginales (Núñez y Dillehay, 1995, p. 27). Esta actividad se presenta bajo los patrones de la movilidad giratoria señalada por Núñez y Dillehay (1995), donde se producen movimientos "exploratorios de larga distancia" sin alcanzar niveles de sedenterización estables antes de los 5.000 años a.C. Así, en el período arcaico, entre 8000 y 1800 a.C., se produce "una explotación incipiente de zonas ecológicas locales o enclaves más productivos, por grupos andinos y costeños" (Núñez y Dillehay, 1995, p. 56), donde la explotación de recursos marinos comienza a generar contacto con grupos de altura. Posteriormente, en el primer período de amplificación, entre 1800 y 900
a.C., se establecen pequeños asentamientos permanentes a lo largo de zonas eficientes de desembocaduras, generando un intensivo tráfico costa-interior, en una movilidad que pudo "haberse restringido al litoral y a las quebradas bajas al oriente de la Pampa del Tamarugal" sin necesariamente tener contacto o acceso con el altiplano, pero produciendo asentamientos con un patrón arquitectónico permanente y disperso que viene a caracterizar la ocupación en el litoral (Uribe, 2009, pp. 8-14). Ya para la segunda amplificación, entre 900 a.C. y 400 d.C., las actividades productivas incrementan la competencia agromarítima, produciendo un "proceso de interacción étnica y mestizaje costeño-altiplánico a través del establecimiento del nuevo medio de vida aldeano agrariotemprano en las tierras bajas", logrando un desarrollo de patrones corresidenciales en el litoral desértico a través de "la mezcla de explotaciones agrarias y marítimas" (Núñez y Dillehay, 1995, pp. 70-71). Producto del mestizaje y de la interacción de tradiciones locales marítimas y agrarias, en el tercer período de amplificación, entre 400 y 1000 d.C., se produce la formación de etnias costeñas y la "convivencia de poblaciones altas y bajas unidas por los anhelos de complementación", accediendo a "espacios agrarios disponibles y a excedentes locales marítimos" (Núñez y Dillehay, 1995, p. 90) en zonas de alta productividad a lo largo de la costa, complementándose en un macrosistema integrado de control vertical con un máximo de pisos ecológicos (Murra, 1975). Para el período de amplificación cuatro, entre 1000 y 1450 d.C., los tráficos interregionales se consolidan y las "caravanas habrían sido organizadas y controladas por comunidades urbanas y habrían utilizado los asentamientos centralizados como estaciones terminales" (Nuñez y Dillehay, 1995, p. 106), consolidando las relaciones con Tiwanaku en ámbitos religiosos y comerciales. Finalmente, en la quinta fase de amplificación, entre 1450 y 1525 d.C., la ocupación inca aprovecha las redes de movilidad preexistentes y amplía su imperio llegando hasta las costas tarapaqueñas, donde el enterramiento Qhapaq Hucha en Cerro Esmeralda es evidencia de comunicación hasta las tierras bajas.

\section{AVANCE DE LAS MOVILIDADES EN LA COLONIA}

En tiempos coloniales, lo que se denominaba Tarapacá comprendía desde la quebrada de Camarones al norte, hasta el río Loa al sur (Sanhueza, 2008, p. 60). Es en este espacio donde los españoles utilizaron las mismas rutas que usaban los incas para realizar su control por el Tawantinsuyu. Los constantes flujos de intercambio de excedentes entre distintos sectores productivos y mitimaes pescadores y agricultores, nos señala que "esta movilidad colonial parece estar dando cuenta de la continuidad de ciertos patrones tradicionales de acceso a espacios y recursos locales" (Sanhueza, 2008, p. 62). La actitud nómada de buscar nuevos lugares tiene directa relación con la apropiación de nuevos espacios, donde el transhumar necesita de una detención para posteriormente continuar la ruta, instaurándose dinámicas de cooperativismo e interrelación que promueven el diálogo.

La experiencia local prehispánica e histórica del trabajo en metales' permitió la aparición de espacios de socialización y desarrollo productivo. Además de la explotación del cerro San Agustín de Huantajaya, en Tarapacá también se trabajaban minerales como Santa Rosa y El Carmen, en donde "la principal dificultad en el beneficio de la plata eran los costos de transporte y la carestía de insumos y alimentos para la mano de obra. Estos rubros tenían que llegar desde los oasis de los

Es sabido que con anterioridad a la llegada de los españoles, la mina de Huantajaya ya tenía un trabajo de explotación, espacio que posteriormente fue redescubierto de acuerdo a dos versiones; primero por portugueses que acompañaban a Almagro y el "dateo" a Juan de Loayza, y una segunda versión más documentada atribuida al trabajo de Lucas Martínez de Vegazo en la encomienda cedida por Francisco de Pizarro. Desde esta realidad parece importante señalar por ejemplo la atribución a José Basilio como el propagador de la devoción a la Virgen del Carmen, donde tuvo su origen la actual fiesta religiosa de La Tirana (Gavira, 2005). 
1. Camino tropero en Pampa Chiza. Fotografía del autor.

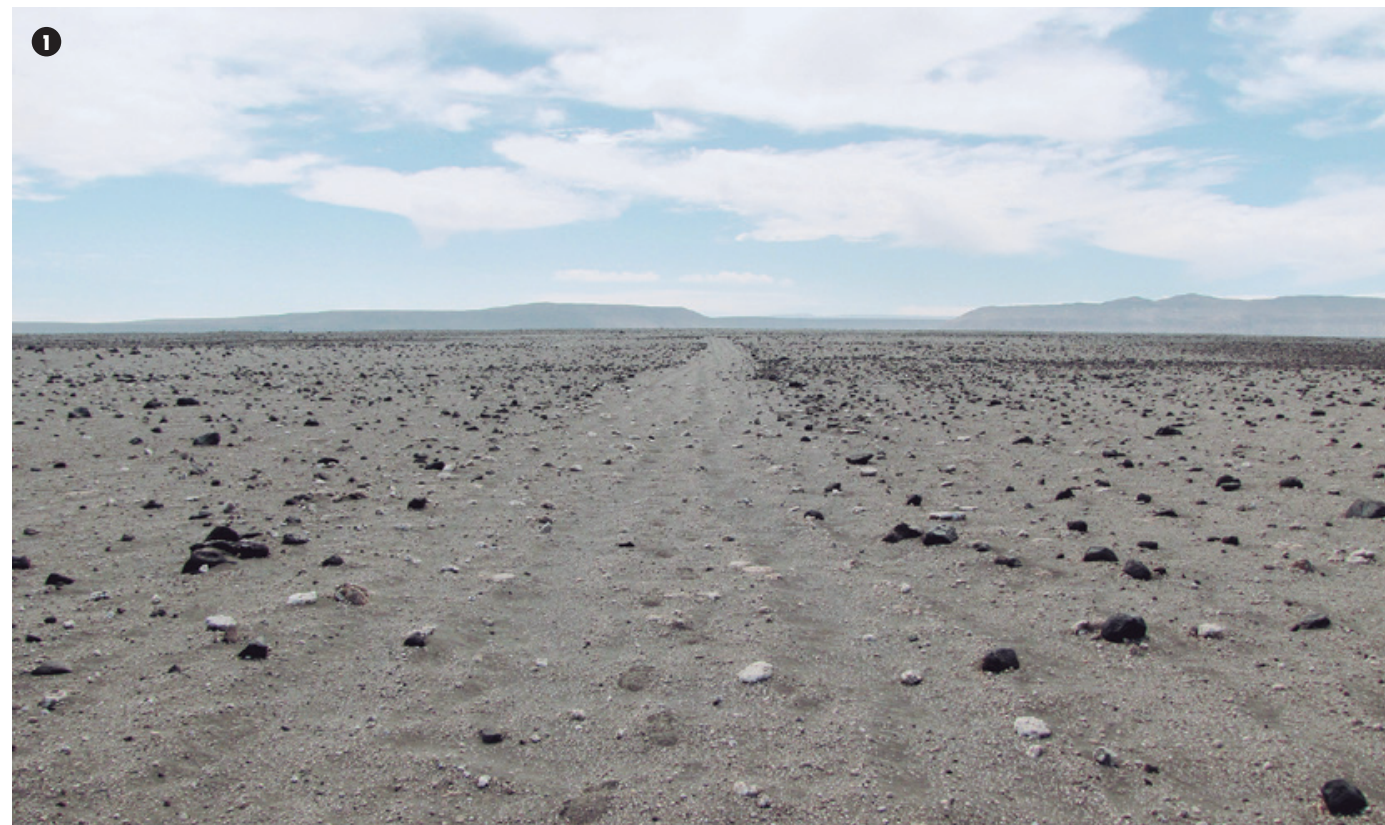

alrededores o del altiplano" (Gavira, 2005, p. 40). La misma movilidad presente desde los procesos formativos del desarrollo tarapaqueño se visualiza con la extracción de metales, fortaleciendo las relaciones en torno a ejes productivos. Esta expresión social del territorio también aparece en los procesos vinculados a la extracción del salitre, en donde la gran movilidad en la Pampa del Tamarugal permitió el origen y consolidación de asentamientos.

La pervivencia de la movilidad tarapaqueña, con evidencias materiales de cada proceso productivo asociado al desarrollo regional y su consecuente consolidación en nodos, también se evidencia con el despliegue de espacios para la detención, que son vestigios de la existencia de actividades vinculadas por una manera de habitar el territorio.

\section{DETENCIÓN Y ARQUITECTURA EFÍMERA EN TARAPACÁ}

La transhumancia en el territorio, es la forma de relacionarse con los espacios que existen entre nodos, entendiéndose el macro sistema de conectividades como la estructura vial de un sistema de lógicas urbanas a escala regional. Los espacios internodales donde se manifiesta la movilidad se presentan como periferia. La escala del desierto y las referencias geográficas en el territorio delimitan las distancias en una compresión macroescalar donde no hay espacio para el vacío. El acto de atravesar el desierto le otorga existencia, sus habitantes aún en movimiento no solo lo utilizan con fines prácticos sino también se exigen nombrarlo para "hablarlo, caminarlo, transformarlo" (González, 2013, p. 116). En este macroterritorio es donde se desenvuelve el andar, debido a que la domesticación del paisaje con pequeños elementos o significaciones a lo geográfico permite que la movilidad se realice en un espacio conocido. No obstante, en el recorrido de las largas distancias aparece "la decisión de detenerse para construir un espacio de encuentro" (Careri, 2002, p. 167). Como vestigios de la movilidad tarapaqueña, podemos encontrar caminos troperos y huellas caravaneras que establecieron el sistema vial utilizado hasta comienzos del siglo XX.
Históricamente el tránsito ha necesitado de detenciones, que se manifiestan en una serie de elementos de acuerdo al ecosistema al que pertenecen, es así como podemos encontrar apachetas $^{2}$ en el altiplano, campamentos de camadas $^{3}$ en la precordillera, pozos ${ }^{4}$ e hitos en la pampa y conchales ${ }^{5}$ en la costa, ejemplos citados como vestigios de una arquitectura efímera prehispánica.

Complementariamente a las detenciones en espacios periféricos, los asentamientos también sufren modificaciones por la llegada de habitantes que consideran la estructura urbana como soporte transitorio. Evidencia de ello es el caso de las localidades de Tarapacá y La Tirana para las fiestas de devoción a San Lorenzo y Virgen del Carmen respectivamente, donde el gran aumento demográfico transforma la configuración de habitabilidades esporádicas por cuanto dinámicas de movilidad se presentan, apareciendo una nueva forma de relacionarse con este espacio, replicando dinámicas propias de los nodos pero utilizando el encuentro para configurar una relación espacial propia de la detención.

Revisando brevemente el caso de La Tirana, vemos que desde mediados del siglo XVIII ha sufrido modificaciones en su configuración urbana, iniciando su estructura con una serie de buitrones y consolidándose con la edificación

2 Montículo de piedras llevadas por los viajeros para descargar en ella su cansancio, bajo la protección de la deidad de los caminos. Se ubican en el borde de las antiguas huellas de tránsito.

3 Recintos regulares ligeramente ovalados que se confeccionaron excavando el suelo pedregoso y amontonando material en los bordes, en algunos casos reforzado con piedras por uno de los lados del recinto (Briones, Núñez y Standen, 2005).

4 Recurso utilizado por los antiguos caminantes para aprovechar el agua de los aluviones (huaycos) conservando, por espacio de varios meses, el agua fresca para diversos usos.

5 Basurales conchíferos con diferentes estratos donde se encuentran abundantes restos de moluscos, de aves, pescado y mamíferos marinos, junto a diverso material cultural (Urbina, Adán, Moragas, Olmos, y Ajata, 2011) 
2. Arquitectura de la Movilidad. Camada en Alto Ariquilda norte. Fotografía del autor.

3. Arquitectura de la Movilidad. Detalle de Conchal en Patache. Fotografía del autor.

4. Campamento en Poblado de la Tirana años 50-60. Fuente: Biblioteca digital Universidad de Chile.

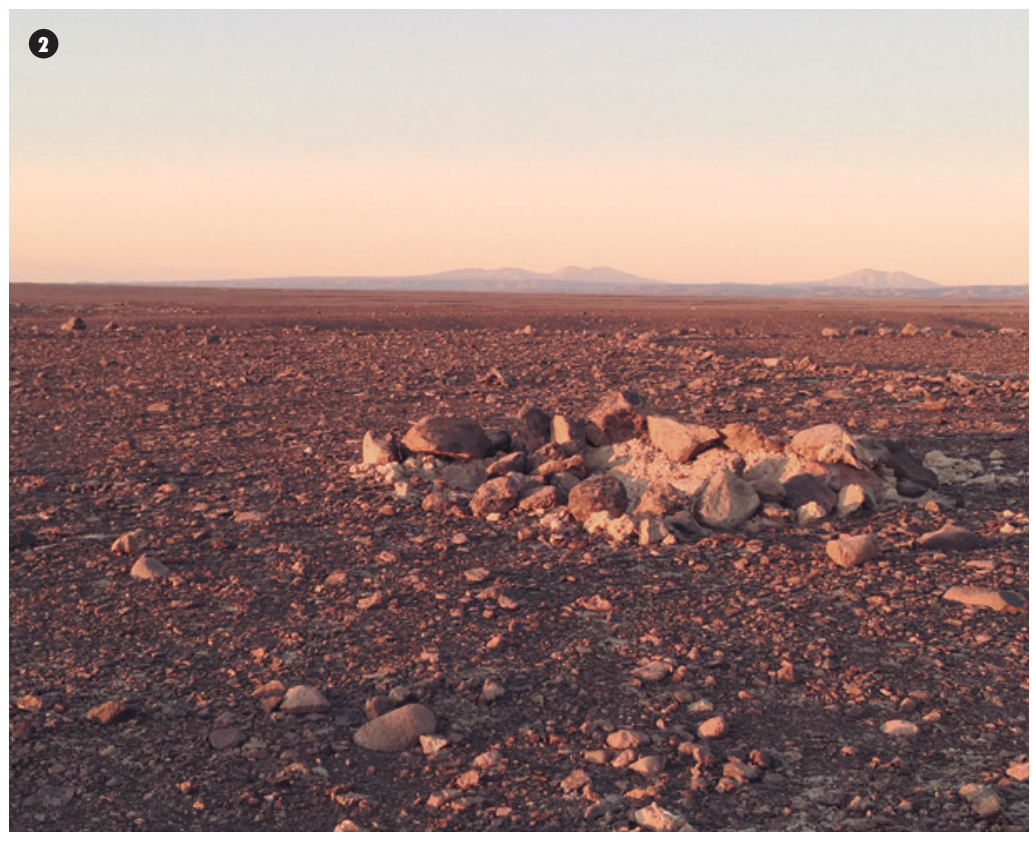

de la primera iglesia a un costado del "Pozo del Carmen" en el período republicano. El culto mariano que data de mediados del siglo XIX y el traslado de la iglesia hasta el emplazamiento actual (comienzos del siglo XX) han aportado a la conformación del pueblo de La Tirana como un lugar de devoción a escala nacional.

Actualmente la densidad de construcciones existentes en La Tirana no concuerda con el número de habitantes estables. El carácter de transitoriedad en el uso de viviendas, está directamente ligado a la participación en festividades propias de la localidad. No se puede entender la tradición edificatoria a través de un estilo arquitectónico particular, ya que la constante evolución de las mismas responde a un desarrollo en el tiempo, de elaboración momentánea, ligera y modificable, supeditada a materialidad disponible. Estas manifestaciones arquitectónicas actuales son consecuencia de un proceso que ha tomado años, donde las distintas generaciones de habitantes han ido consolidando sus estructuras habitables. Las carpas que se levantan van rearmando el pueblo en función de la festividad. La ocupación efímera se manifiesta arquitectónicamente desde sus inicios a través de campamentos (FIGURA 4), costumbre presente hasta el día de hoy. Mientras la fiesta se desarrolla, las calles del poblado se peatonalizan y llenan de gente, refugios temporales y puestos de venta emergen al servicio de la procesión de la Virgen del Carmen (Mehrotra y Vera, 2016).
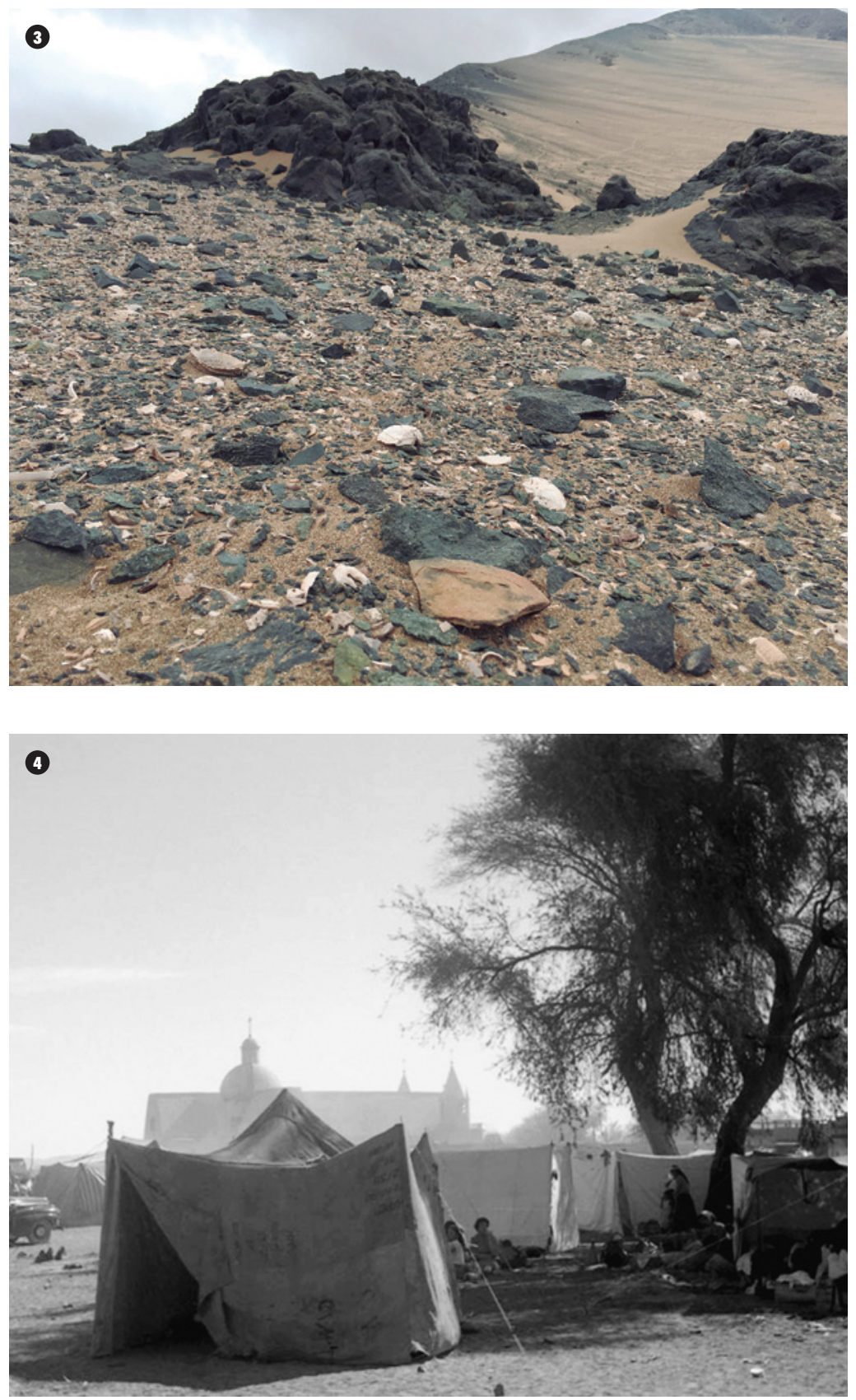


\section{LA CONEXIÓN DEL BORDE COSTERO SUR DE IQUIQUE}

Puntos productivos de la costa tarapaqueña en el sur de lquique estuvieron conectados con el interior de la región desde épocas prehispánicas y aún hasta el siglo XIX un trazado longitudinal que conectara dichos puntos era inexistente. Es en la segunda mitad del siglo $X X$ cuando se empieza a consolidar un camino desde lquique hacia el sur, para el año 1957 el camino solamente llegaba hasta Huanillos y transitarlo completamente demoraba alrededor de 6 horas. Gracias al poblamiento de caletas como Patillos, Chanavayita, Chucumata y Quinteros, para el año 1965 se podía llegar hasta el Río Loa por vía terrestre, consolidándose su conexión hasta Tocopilla para comienzos de la década de 1970. La generación de un camino que conectara la red de caletas entre lquique y el Loa venía a dar respuesta a una necesidad operativa, esto ya que el vehículo era un recurso común en la ciudad gracias a la ley de importaciones para zonas extremas de la década del ' 60 . A consecuencia de ello dejan de usarse las embarcaciones que visitaban caletas y proveían de agua y víveres a quienes allí habitaban.

La conexión del iquiqueño con el borde costero posee evidencias en actividades urbanas del lquique de comienzos del siglo XX, la creación de un camino hasta punta Cavancha y la aparición de baños públicos son respuesta a ello. En el año 1950 el sistema de ocupación de borde en período estival (FIGURA 5) muestra un uso determinado por estructuras livianas y autosoportantes cubiertas de tela blanca, como se ve en la imagen de Playa Cavancha.

El uso del borde mas allá del límite urbano ya era común durante la década de 1940, para entonces se realizaban paseos al sector de Primeras Piedras, donde además del baño recreacional se efectuaban excursiones al Cerro Dragón. Gracias a las posibilidades viales de conexión generadas en la década de 1960 y el poblamiento de algunas caletas, el acceso a playas alejadas se vuelve común. Como

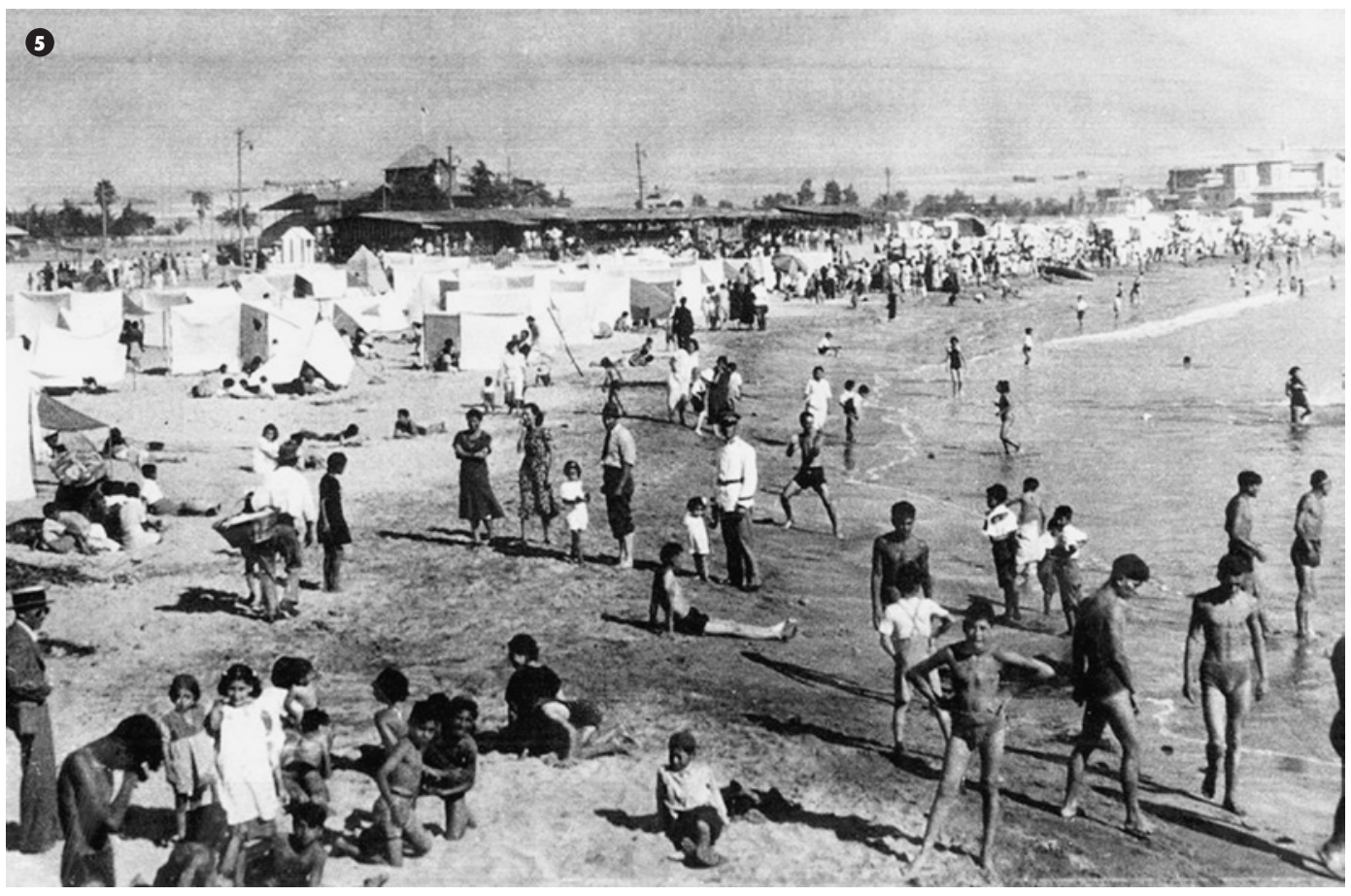

iniciadores de travesías con diferentes destinos comprendidos entre lquique y el río Loa cabe mencionar a los grupos de amigos "Los Pineles" y "Huracán", quienes desafiando las precarias conexiones se aventuraban durante semanas, con las provisiones precisas y el ímpetu de saber que el mar proporcionaba gran parte de la alimentación; pescando chalacos, tomoyos, cabrillas y algunos lenguados; extrayendo erizos, locos, lapas y apretadores. Para los inicios de la década de 1970, ya se podía ver familias realizando campamentos en algunas playas.

\section{FORMAS DE OCUPACIÓN EFÍMERA EN EL BORDE COSTERO}

El borde costero al sur de lquique posee variadas instancias de ocupación: las caletas, el aeropuerto y los puertos, un espacio de vínculo afectivo humanizado como el cementerio de mascotas y otro de carácter religioso como el Parque Bicentenario Punta Gruesa, la cancha de golf como equipamiento deportivo; vestigios de ocupaciones históricas como la ballenera (explotación de cetáceos) y el castillo de Huanillos (explotación del huano), y otras transitorias como la misa del Papa Francisco en enero de 2018. Pero por otra parte, las actuales apropiaciones de playas durante el período estival poseen un atributo en común, la lógica de la reversibilidad. Este situarse en conjunto nos habla de una manera de entender la detención, la creación de una estructura urbana de escala menor, flexible, versátil y abierta al cambio, también responde a una organización y respuesta lógica a las condiciones particulares de cada emplazamiento.

Las agrupaciones que surgen en cada una de las playas no responden a casualidades. Anualmente las mismas familias se trasladan a los mismos lugares, ahí es donde estos nuevos paisajes temporales, también son "formas de proveer espacio y lugar a la conservación de tradiciones sociales, realzando valores de cohesión y permitiendo interacciones a manera de encuentro catártico" (Mehrotra y 
6. Estrategias de ocupación tarapaqueña del borde costero. Fotografías del autor.
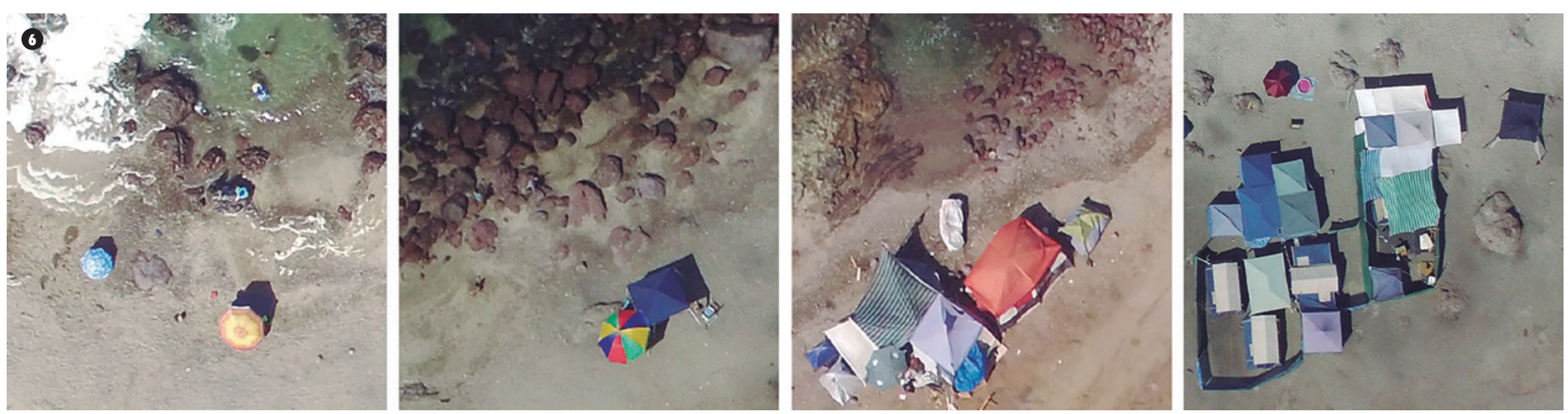

Vera, 2016, p. 36). Los diferentes patrones de conformación de la estructura urbana a menor escala será definida en el presente artículo como microurbana, ya que consideran un entorno ambiental de carácter urbano, con servicios de comercio asociado y comodidades propias de lo urbano; como extracción de basura, acceso a agua potable y servicios sanitarios (estos último llevados por los propios habitantes o en algunas playas, dispuestos por el municipio).

Asimismo, presentan un carácter efímero, que permite realizar una lectura de reconocimiento formal para visualizar agrupaciones, vínculos, superposiciones e intersecciones que son indicadores de operaciones sociales de apropiación, la manifestación de una herencia cultural.

La ocupación del litoral tarapaqueño en el período estival se puede sintetizar en dos estrategias: una que se realiza de manera aislada y otra que responde a una intención colectiva. En ambas podemos ver que "la simplicidad del sistema constructivo no solo facilita el armado, reconfiguración, y desarme en terreno, sino que también facilita la logística y los canales de distribución de cada componente y pieza" (Mehrota y Vera, 2015, p. 21). Las estrategias de ocupación en estructuras de configuración microurbana, se establecen en función de una estadía con caducidad temporal predeterminada, acompañado de condiciones de habitabilidad. Las cuatro estrategias identificadas son: Aislada Individual, que tiene un tiempo de ocupación entre 1 hora y 1 día, realizada de 1 a 5 personas con el fin de generar actividades relativas al ocio, estableciéndose materialmente con elementos sin complejidad de armado como quitasoles o carpas de playa; Aislada Colectiva, que se presenta como una ocupación diaria hasta entrada la noche, realizada aproximadamente por 2 a 10 personas, las que se establecen con elementos sin complejidad de armado y de fácil desarme como quitasoles grandes y toldos plegables, haciendo uso de la playa con fines recreativos y ocasionalmente para extraer productos marinos (pescados y/o mariscos); Conjunto Individual se establece entre un fin de semana y dos o tres semanas, por uno o más de un núcleo familiar, utilizando carpas, toldos plegables y listones de madera para proteger el perímetro con mallas textiles, allí se cocina lo mismo que en casa, trayendo víveres desde la ciudad que se complementan con la extracción de productos marinos; y Conjunto Colectiva se desarrolla desde dos semanas a todo el período estival por varios núcleos familiares, donde materialmente se conforman igual que la estrategia anterior pero sumándose artículos eléctricos y baño portátil para poseer mayores comodidades, en cuanto a alimentación también complementan víveres con extracción de productos marinos.
Las condiciones de ocupación varían según la playa. La medida mínima está dada por el quitasol, mientras que la máxima se va extendiendo en base al toldo, donde la sumatoria de estos y un pensado distanciamiento otorga espacios comunes para el desarrollo de la vida diaria. Playa Lobito se presenta (FIGURA 7) como una gran explanada que permite una ocupación mayoritariamente aislada y su relación con el borde no presenta condiciones propicias para la extracción de recursos marinos, por lo que los habitantes se apropian por tiempos limitados de la costa. Por otra parte, podemos ver que playa Palo de Buque (Figura 8) presenta un borde rocoso con condiciones necesarias para extracción de recursos marinos y hacer uso de la playa como balneario, de esta manera su ocupación se presenta mayoritariamente a través de estrategias colectivas que muestran una manera prolongada de apropiarse del borde costero.

Podemos ver todas las estrategias de ocupación en la construcción de un espacio efímero (FIGURA 10), donde se dificulta la comprensión de división de espacios pertenecientes a familias y comercio presentes en la ocupación temporal, ya que la conformación Conjunto Colectivo determina una imagen de conjunto cohesionada formal y espacialmente, lugar donde las prácticas culturales son compartidas y las actividades se suceden con mayor compresión colectiva. 
7. Playa Lobito, verano 2017. Mayoritariamente ocupación aislada. Fotografía del autor.

8. Playa Palo de Buque, verano 2017. Mayoritariamente ocupación en agrupamiento. Fotografía del autor.

9. Playa Palo de Buque. Panorámica de la ocupación. Fotografía del autor.

10. Playa Palo de Buque, verano 2018. Desarme de la ocupación. Fotografía del autor.
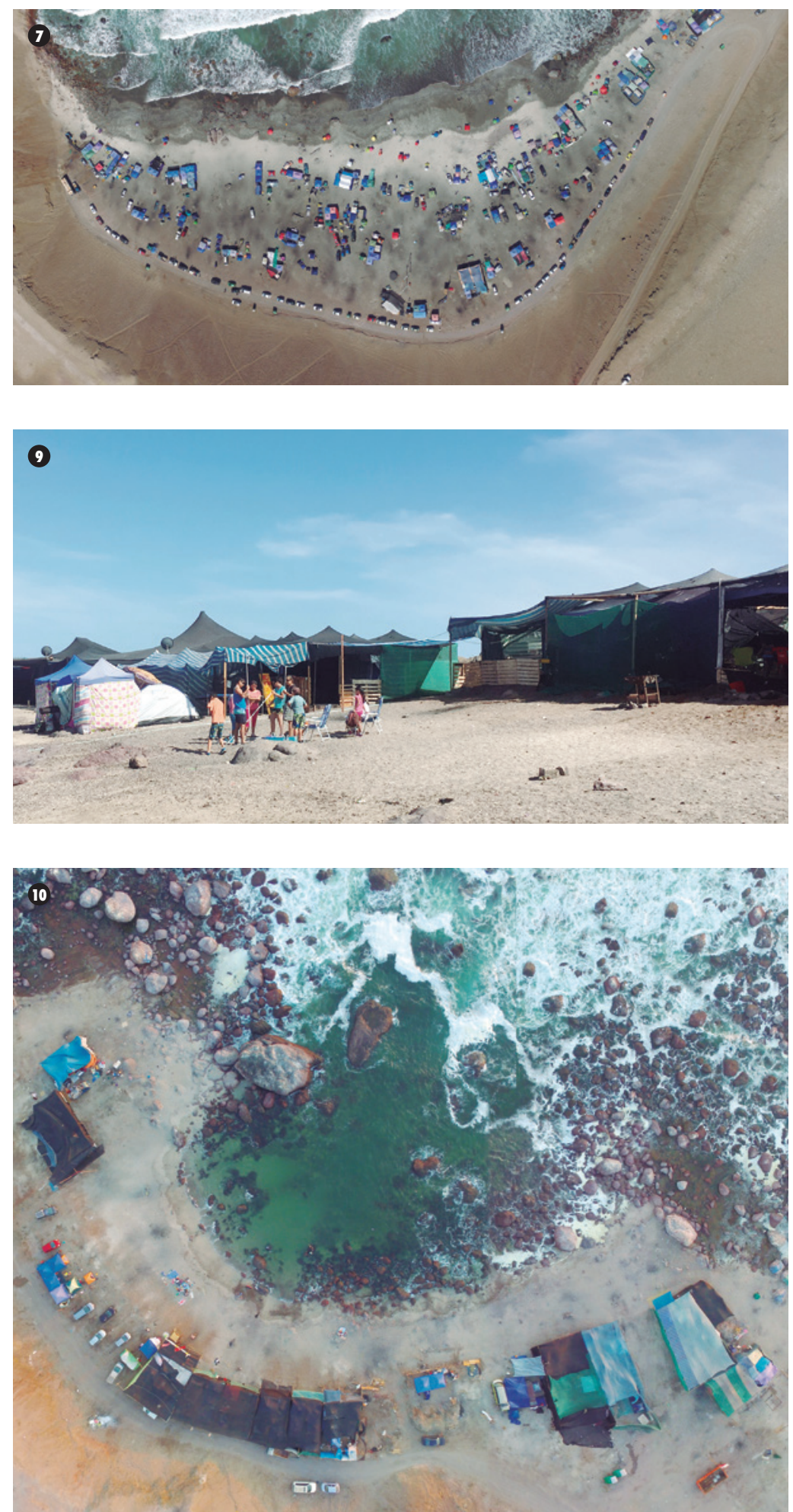

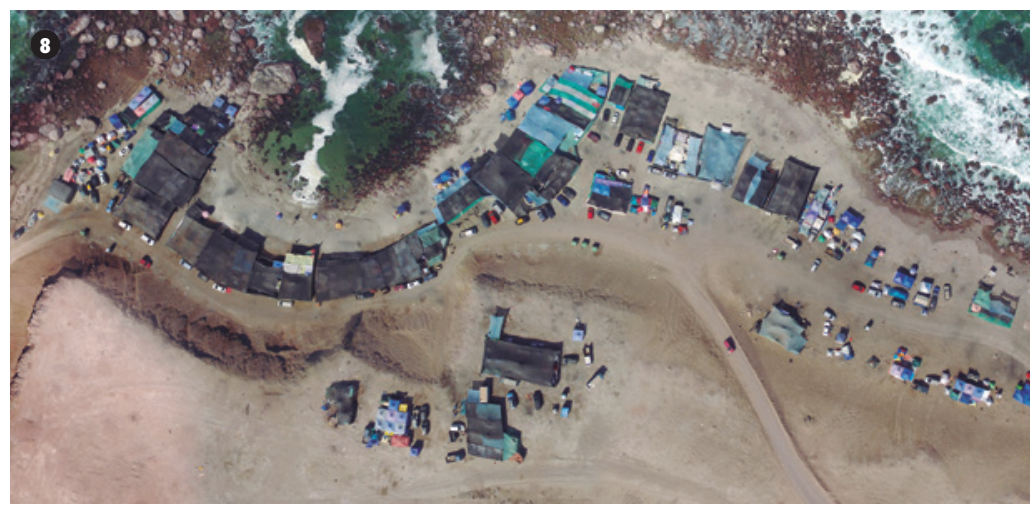

\section{PAISAJE CULTURAL Y DESPLAZAMIENTO}

En la conformación de microurbanismos efímeros en la costa tarapaqueña se han desarrollado expresiones culturales que contribuyen a la definición de una identidad cultural particular, diversas prácticas del espacio con distintas ocupaciones y actividades que se hacen operativas en tres sectores: el económico, el político y el sociocultural (Garcés, Moraga y Maureira, 2016). En el caso de playa Palo de Buque participan tres generaciones de familias que cada año usan los mismos lugares y trabajan para conservar el lugar de sus vacaciones. Pese a que sufrieron violentos desalojos, negociando derechos de uso del espacio y fueron víctimas de constantes robos; durante más de 2 décadas han fortalecido su paisaje cultural trasladándose allí cada verano; renombrando la geografía, modificando el suelo trayendo arena de Playa Blanca, realizando juegos para fortalecer la convivencia, consolidando un espacio para contribuir a la concientización de la conservación ecológica en las generaciones más jóvenes y desarrollando un carnaval propio que ha contado con la participación de artistas locales. En este contexto temporal, es posible apreciar cómo se integran en un espacio geográfico, las relaciones culturales que van dejando vestigios materiales e inmateriales que se constituyen en referentes de identidad (Beltrán, 2012).

Actualmente las estrategias de ocupación veraniega pueden verse en Tres Islas, Playa Blanca, Punta Gruesa, Palo de Buque, Lobito y Los Verdes, las cuales se enfrentan ante una posibilidad de desplazamiento por cuanto pueden integrarse al área urbana de crecimiento de la ciudad de lquique. El municipio ha encargado el estudio para la actualización del Plan Regulador de lquique; considerando las bases administrativas de licitación, la consultora que se adjudicó el estudio ha expresado la voluntad por actualizar las condiciones del área urbana vigente y analizará la ampliación del límite urbano incorporando los sectores de crecimiento ubicados hacia el sur de la ciudad, tales como Bajo Molle, Tres Islas, Playa Blanca, Lobito, Los Verdes. Justamente en relación a esta discusión es, de 
acuerdo a lo que plantea Beltrán (2012), que este instrumento de planificación debería tener una visión de conjunto sobre la protección de los recursos culturales para impulsar el desarrollo, cohesionar socialmente a las comunidades y elevar su dignidad humana a partir del uso y disfrute equilibrado de sus recursos culturales, y así también proteger los valores inmateriales y abordar el ambiente desde una mirada ampliada (Galimberti, 2016).

\section{DISCUSIÓN}

La tradición de la movilidad en Tarapacá se presenta como una actividad patrimonial de carácter intangible, ya que tanto la prehispánica, histórica y contemporánea poseen la misma estrategia de vinculación. El territorio se manifiesta habitado en toda su extensión y por ello se pudo desarrollar la movilidad en los espacios internodales. No es hasta mediados del siglo XX que la necesidad de conectar vía terrestre los territorios costeros resulta en la configuración de la ruta lquique-Río Loa, permitiendo finalmente a los habitantes poder desplazarse y comenzar la apropiación del borde costero.

La apropiación de playas por largos períodos durante los veranos comenzó en la década de 1960 y se mantiene hasta los días presentes. Los criterios de ocupación van obedeciendo a las circunstancias temporales dispuestas para habitar el borde costero, desde ahí que tanto las ocupaciones aisladas como las agrupadas guardan relación con lo efímero y la urbanización a microescala, donde la arquitectura se adapta al programa específico de los habitantes.

El crecimiento sur de la ciudad de lquique hasta Los Verdes otorgaría carácter urbano a espacios que hasta el momento se mantienen a disposición libre de ocupación temporal, lo que conllevaría al uso de la movilidad costera con el fin de apropiarse de playas que hasta el momento no poseen mayor desarrollo de agrupamiento colectivo durante los veranos, reforzando la idea de Tarapacá como espacio habitado en toda su extensión y la costa como un espacio internodal para el desarrollo de la arquitectura de la detención en los tiempos actuales.

\section{CONCLUSIONES}

Consecuencia de la movilidad actual, entendida como actividad tradicional, se presenta la ocupación estival costera como manifestación de herencia cultural dinámica, expresión viva de una tradición local que recoge elementos inmateriales del patrimonio regional y nos conduce a la comprensión de una manera particular de relacionarse con el territorio, donde no se presenta enajenación de la condición de uso público en el espacio ocupado, contrariamente a lo experimentado en otras partes del país donde la ocupación se consolida privatizando accesos o apropiándose indefinidamente del borde costero.

Si bien la actualización del Plan Regulador de lquique se enfoca en la protección de recursos de Valor Natural y Patrimonial Cultural, implementando Áreas de Protección de Recursos de Valor Natural y Áreas de Protección de Recursos de valor Patrimonial Cultural, esto se realiza con la determinación de Zonas de Conservación Histórica y la protección de Inmuebles de Conservación Histórica, por lo que no contempla protección para zonas donde se realicen actividades propias de la cultura intangible local, resultando que en los espacios donde se realiza el veraneo costero se implementen normativas de uso de suelo al pasar a estar dentro del nuevo límite urbano comunal.
Independiente de los resultados que arroje la actualización del PRC y del inminente desplazamiento del veraneo en estructuras efímeras microurbanas de las zonas comprendidas dentro del límite urbano, será interesante ver como la movilidad de la actividad patrimonial veraniega se adapta a la nueva normativa y logre visualizarse como la regulación afecta o no el paisaje cultural local del cual son parte.

\section{REFERENCIAS BIBLIOGRÁFICAS}

Beltrán, L. (2012). El significado cultural de las regiones, articulación del patrimonio cultural material e inmaterial como impulso para el desarrollo humano. Apuntes. Revista de estudios sobre patrimonio cultural, 25 (1), 6-7. Disponible en: http://revistas.javeriana.edu.co/index.php/ revApuntesArq/article/view/8828/7028

Briones, L.; Núñez, L. y Standen, V. (2005). Geoglifos y tráfico prehispánico de caravanas de llamas en el desierto de atacama (Norte de Chile). Chungará, 37(2), 195-223. http://dx.doi.org/10.4067/ S0717-73562005000200007

Careri, F. (2002) Walkescapes, el andar como práctica estética. Barcelona, España: Editorial Gustavo Gili.

Carevic, A. (2013) Aplicación del Modelo de Desarrollo productivo endógeno sustentable en comunidades campesinas de la provincia del Tamarugal, Región de Tarapacá. Iquique, Chile: GRACAM editores.

Garcés, A, Moraga, J., y Maureira C, M. (2016). Tres movilidades para una ruta: Espacio, comercio y transnacionalidad boliviana en Tarapacá. Estudios Atacameños, (53), 205-220. http://dx.doi. org/10.4067/S0718-10432016005000010

Galimberti, C. (2016). El patrimonio territorial como mirada integral del ambiente. Análisis del frente fluvial metropolitano de Rosario. Apuntes. Revista de estudios sobre patrimonio cultural, 28(2). http://dx.doi.org/10.11144/Javeriana.apc28-2. ptmi 
Gavira, M. C. (2005). Producción de plata en el Mineral de San Agustín de Huantajaya (Chile), 1750-1804. Chungará, 37(1), 37-57. http://dx.doi.org/10.4067/S071773562005000100004

González, S. (2013). La Sociedad del Salitre, Protagonistas, migraciones, cultura urbana y espacios públicos 1870-1940. Santiago, Chile: Ril Editores.

Mehrotra, R, y Vera, F. (2015). Reversibility: Desmontando la mega-ciudad efímera más grande del mundo. $A R Q,(90), 14$ 25. http://dx.doi.org/10.4067/S0717. 69962015000200003
Mehrotra, R. y Vera, F. (2016). Ephemeral Urbanism: Cities in constant flux. Santiago, Chile: Ediciones $A R Q$.

Murra, J. (1975). Formaciones económicas y políicas del mundo andino. Lima, Perú: Instituto de Estudios Peruanos Ediciones.

Núñez L y Dillehay T. (1995). Movilidad giratoria, armonía social y desarrollo de los andes meridionales: Patrones de tráfico e interacción económica. Antofagasta, Chile: Universidad Católica del Norte.

Sanhueza, C. (2008). Territorios, prácticas rituales y demarcación del espacio en Tarapacá en el siglo XVI. Boletín del Museo Chileno de Arte
Precolombino, 13 (2), 57-75. Disponible en: http://scielo.conicyt.cl/pdf/bmchap/v13n2/art04. pdf

Urbina, S.; Adán, L.; Moragas, C.; Olmos, S., \& Ajata, R. (2011). Arquitectura de asentamientos de la costa de Tarapacá, norte de Chile. Estudios atacameños, (41), 63-96. http://dx.doi. org/10.4067/S0718-10432011000100005

Uribe, M. (2009). El período Formativo de Tarapacá y su cerámica: Avances sobre complejidad social en la costa del norte grande de Chile (900 AC-800 DC). Estudios atacameños, (37), 5-27. http://dx.doi.org/10.4067/S071810432009000100002 